Revue des patrimoines

6 | 2005

Patrimoine en situation : l'Inventaire général entre histoire et prospective

\title{
Le recensement du patrimoine mobilier des églises de l'Aube
}

Xavier de Massary et Bruno Decrock

\section{(2) OpenEdition}

Journals

Édition électronique

URL : http://journals.openedition.org/insitu/9168

DOI : $10.4000 /$ insitu.9168

ISSN : 1630-7305

Éditeur

Ministère de la culture

Référence électronique

Xavier de Massary et Bruno Decrock, "Le recensement du patrimoine mobilier des églises de l'Aube », In Situ [En ligne], 6 | 2005, mis en ligne le 01 septembre 2005, consulté le 20 avril 2019. URL : http:// journals.openedition.org/insitu/9168; DOI : 10.4000/insitu.9168

Ce document a été généré automatiquement le 20 avril 2019

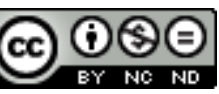

In Situ Revues des patrimoines est mis à disposition selon les termes de la licence Creative Commons Attribution - Pas d'Utilisation Commerciale - Pas de Modification 4.0 International. 


\title{
Le recensement du patrimoine mobilier des églises de l'Aube
}

\author{
Xavier de Massary et Bruno Decrock
}

L'enquête menée de 2002 à 2005 sur le patrimoine mobilier du département de l'Aube se voulait exemplaire et innovante à plus d'un titre :

- par son objectif ambitieux, consistant à recenser en trois ans l'ensemble du mobilier des églises du département présentant un intérêt artistique, qu'il soit ou non protégé au titre des Monuments historiques

- par son mode de financement associant à parité l'état, la Région Champagne-Ardenne et le département de l'Aube

- par sa mise en œuvre confiée à un chargé d'études indépendant: Bruno Decrock, sélectionné après appel d'offres, et entouré d'une équipe de chercheurs constituée pour l'occasion (fig. $\left.\mathbf{n}^{\circ} \mathbf{1}\right)$. 
Figure 1

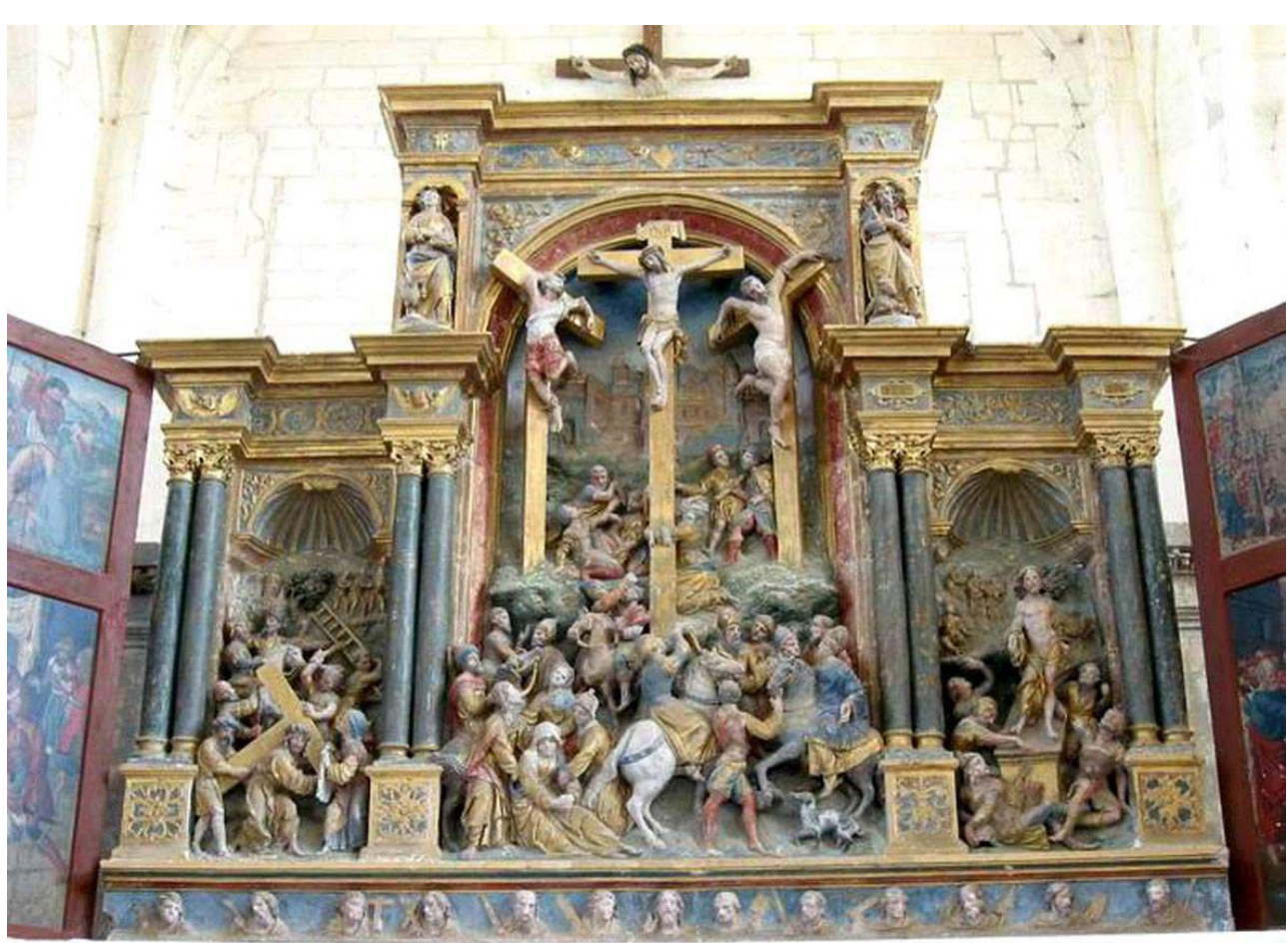

n:

Retable de l'église de Géraudot, 1545.

Phot. F. Griot (c) Ministère de la Culture et de la Communication. Région Champagne-Ardenne.

Département de l'Aube, 2003.

\section{La genèse du projet}

2 La constitution de fichiers informatisés et illustrés du mobilier protégé au titre des Monuments historiques est un objectif pour tous les conservateurs d'antiquités et objets d'art ainsi que pour les conservations régionales des monuments historiques. Selon les départements, des solutions diverses ont été recherchées pour compléter et actualiser l'information donnée par les arrêtés de classement. L'originalité de la mission auboise fut d'intégrer l'ensemble des données au sein du dossier électronique de l'Inventaire ${ }^{1}$, ceci à l'échelle du département, dans le cadre d'une vaste opération de récolement et d'inventaire complémentaire, et dans un délai relativement court de trois années. Apparemment, aucune opération de ce type n'a jusqu'à présent été conduite dans un autre département.

La mise en place du volet culturel du contrat de plan Etat-Région 2000-2006 allait permettre opportunément de trouver de nouvelles sources de financement pour réaliser cet objectif. Alors que la région Champagne-Ardenne ne participait jusqu'alors que ponctuellement à la restauration et à la valorisation du patrimoine culturel ${ }^{2}$, le contrat de plan l'amena à intervenir, à parité avec l'Etat, sur des thématiques définies en commun ; ces deux partenaires de base s'associant à une ou plusieurs autres collectivités en fonction des projets.

4 Trois thématiques ont été retenues : le vitrail, l'architecture fortifiée et la statuaire. C'est sous cette dernière thématique que Xavier de La Selle, conservateur des antiquités et 
objets d'art, et par ailleurs directeur des archives départementales de l'Aube présenta, dès la fin de l'année 1999, au groupe de travail chargé de faire des propositions, le projet de base de données informatisées de l'ensemble du mobilier protégé. Il fixa d'emblée trois objectifs à cette opération :

- fournir un outil de connaissance aux chercheurs en histoire de l'art

- apporter une aide à la gestion et à la restauration des œuvres protégées

- constituer un support au développement culturel et touristique, dans le cadre des politiques d'aménagement du territoire.

5 Lorsqu'il fut présenté le 6 novembre 2000 au comité d'experts chargé de le valider, le projet restait limité aux 4500 œuvres protégées (dont 1500 inscrites). Mais le cahier des charges établi au début de l'année suivante y ajoutait 3000 objets déjà mis en fiches par un précédent conservateur des antiquités et objets d'art ${ }^{3}$ en vue de protections éventuelles ainsi que 2000 œuvres supplémentaires, soit un total de 10000 objets, ce qui représentait plus qu'un doublement par rapport au nombre d'œuvres protégées.

budget de $411612 €$ fut arrêté pour cette opération, alimenté à parité par l'état, la Région et le Département, sur trois exercices (2002, 2003 et 2004). Le maître d'ouvrage en était le Département. A l'issue de l'appel d'offres lancé en mai 2001 et qui donna lieu à trois réponses, le chargé d'études retenu en novembre 2001 par le Département fut M. Bruno Decrock, pour un devis de $361011 €$.

7 Le passage de 10000 à 12000 du nombre de notices, prévisible dès l'issue de la phase de test, auquel s'est ajoutée la nécessité de réaliser des notices de présentation des édifices et de leur contenu, enfin la numérisation complémentaire d'environ 8000 photos anciennes et leur rattachement à la base source ont donné lieu à plusieurs avenants pour un total de $80000 €$ pris en charge par la direction régionale des affaires culturelles de Champagne-Ardenne ${ }^{4}$. Après débat, l'opération prit le titre officiel de « Recensement du patrimoine mobilier des églises de l'Aube».

\section{L'organisation scientifique et technique}

Les aspects méthodologiques et techniques étaient précisés dans le cahier des charges :

- fiches documentaires utilisant le Système descriptif de l'Inventaire général

- photographies numériques de chaque objet, le tout associé à un système d'information géographique.

\section{L'étendue de l'opération}

Il n'était pas possible de circonscrire d'emblée le champ à explorer. Quelques objets protégés ou déjà repérés, à vrai dire en très petit nombre, n'étaient pas liés aux églises et à l'exercice du culte ${ }^{5}$, et si l'on procéda évidemment à leur récolement, seules les églises et chapelles publiques furent soumises à un inventaire systématique, y compris celles où aucune œuvre n'était jusqu'alors repérée.

10 La limite chronologique retenue est celle du concile Vatican II (1962-1965) ; limite qui fut repoussée à la Révolution pour certaines catégories d'œuvres comme, par exemple, les cloches ou les livres.

11 Par rapport à une opération d'inventaire topographique « classique ", ne furent pas prises en compte les œuvres ne relevant pas du mobilier au regard de la réglementation des 
Monuments historiques : les verrières, dont par ailleurs le recensement avait été effectué dans les années 1980 dans le cadre du Corpus Vitrearum ${ }^{7}$, et la plupart des décors portés (chapiteaux, clés de voûte, et encadrements de portes...), sauf s'ils étaient déposés ou s'ils constituaient un élément de décor majeur, notamment figuré comme, par exemple, le tympan sculpté de l'église de Verrières. Les peintures murales firent exception: initialement exclues de l'enquête, elles furent réintégrées sur proposition du prestataire. Cette décision partait d'un double constat: la relative rareté des peintures murales dans le département (leur traitement pouvait donc être intégré sans surcoût), et leur grande fragilité. L'enquête constituait donc l'occasion opportune d'en dresser la liste. (fig. $\mathbf{n}^{\circ} \mathbf{2}$ ) (fig. $\mathbf{n}^{\circ}$ 3)

Figure 2

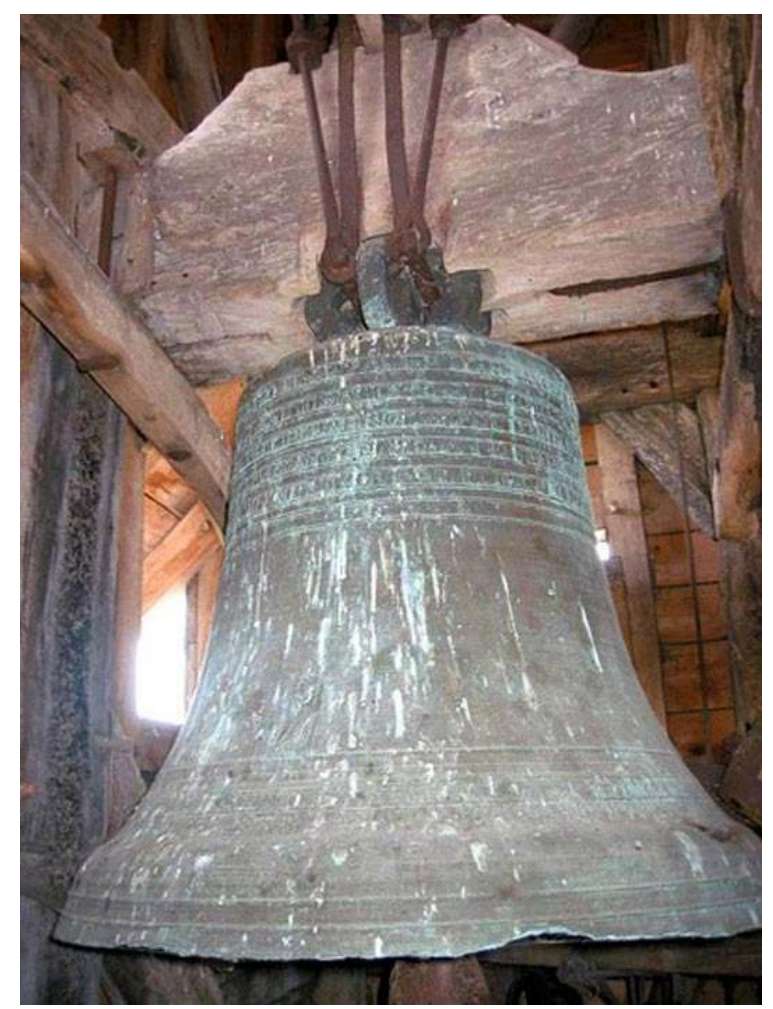

Cloche à Dommartin, 1787

Phot. B. Decrock (c) Ministère de la Culture et de la Communication. Région Champagne-Ardenne.

Département de l'Aube, 2002. 150 cloches ont été recensées. 
Figure 3

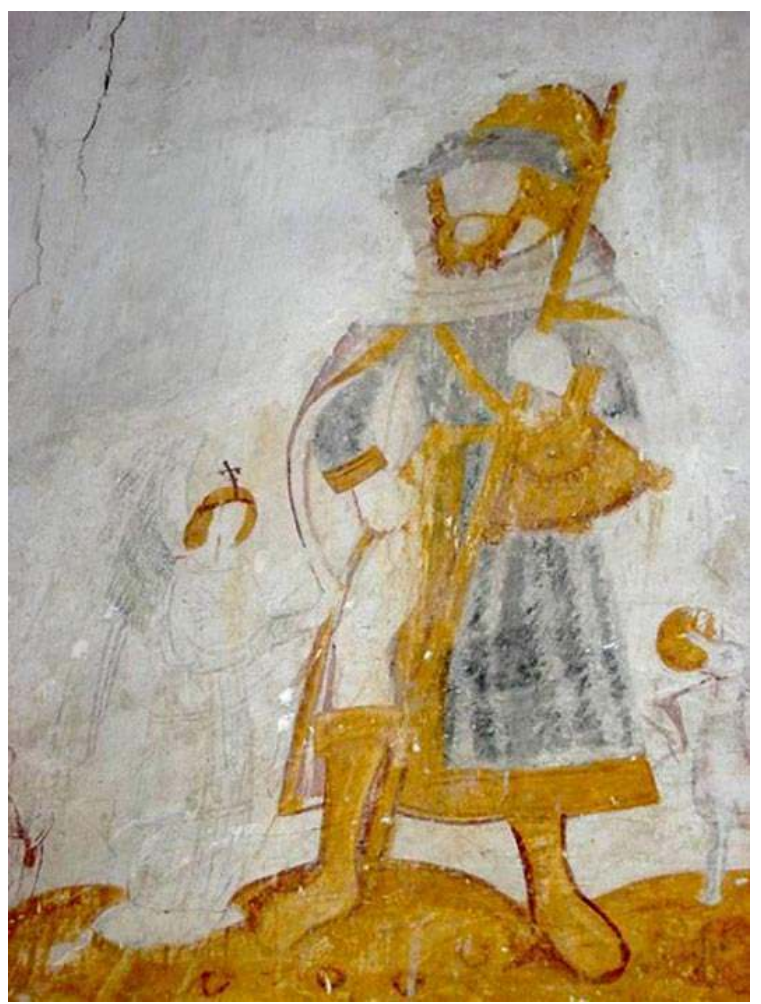

Peinture monumentale à Landreville, 1519, détail : saint Roch.

Phot. R. Caumont de Mesquita (c) Ministère de la Culture et de la Communication. Région ChampagneArdenne. Département de l'Aube, 2003. 138 peintures monumentales ont été recensées.

Un certain nombre de critères, définis dès la phase de test par le comité de suivi, ont guidé les enquêteurs dans leur sélection d'œuvres à retenir.

Devaient être privilégiés :

- les objets documentés, réalisés pour l'édifice où ils se trouvent

- les ensembles bien conservés (autels-retables, même du XIXe siècle, sièges avec leur garniture d'origine, calices avec leur étui d'origine...)

- les objets précieux par leur matériau (ce qui a conduit à recenser massivement les pièces d'orfèvrerie en argent ou en vermeil)

- les objets résultant de la mise en pratique d'une technique affirmée (tissus brodés par exemple), dénotant une « valeur ajoutée » artisanale ou artistique manifeste

- les objets fragiles tels que ceux en tissu ou les livres

- les objets de petites dimensions, particulièrement exposés au vol

14 Les objets singuliers (unica) et/ou témoignant d'habitudes et de pratiques locales, dont l'intérêt est parfois plus sociologique et ethnologique que réellement artistique.

15 La statuaire de série a, en revanche, été systématiquement écartée ; sauf cas particuliers comme les premières œuvres de Léon Moynet, fondateur de la « sainterie » de Vendeuvre (Thil, Ville-sur-Terre). 


\section{Les enjeux scientifiques}

16 Il est évident que la recherche en histoire de l'art a beaucoup à attendre d'une telle entreprise : depuis les travaux de Koechlin et de Marquet de Vasselot au début du XXe siècle, l'école troyenne de sculpture est reconnue comme l'une des plus importantes en France pour la Renaissance. Mais si ses chefs-d'œuvre sont bien connus - du moins des spécialistes, car aucun ouvrage de synthèse ${ }^{8}$, aucune exposition récente n'ont permis pour l'instant de les faire mieux connaître - il reste beaucoup à apprendre sur le contexte artistique de cette floraison, sur ce qui l'a précédée et sur ce qui l'a suivie. La masse des informations attendues devrait permettre d'instructives comparaisons, par exemple, pour la sculpture, entre des œuvres traitant d'un même sujet (la Vierge, les saints ...) ou présentant de fortes parentés stylistiques, mais encore, dans le domaine des arts décoratifs, entre des objets de même type (chaires, lutrins, fonts baptismaux, ...). Des filiations pourront apparaître, mais aussi des évolutions formelles, notamment pour des œuvres aussi complexes que les autels-retables,. Cette moisson de connaissances nouvelles sera sans doute à la hauteur de la richesse du patrimoine mobilier de l'Aube qui a assez peu souffert des guerres du XXe siècle ${ }^{9}$, ce qui explique que ce département occupe le deuxième rang en France par le nombre d'objets protégés. (fig. $\mathbf{n}^{\circ} 4$ )

\section{Figure 4}

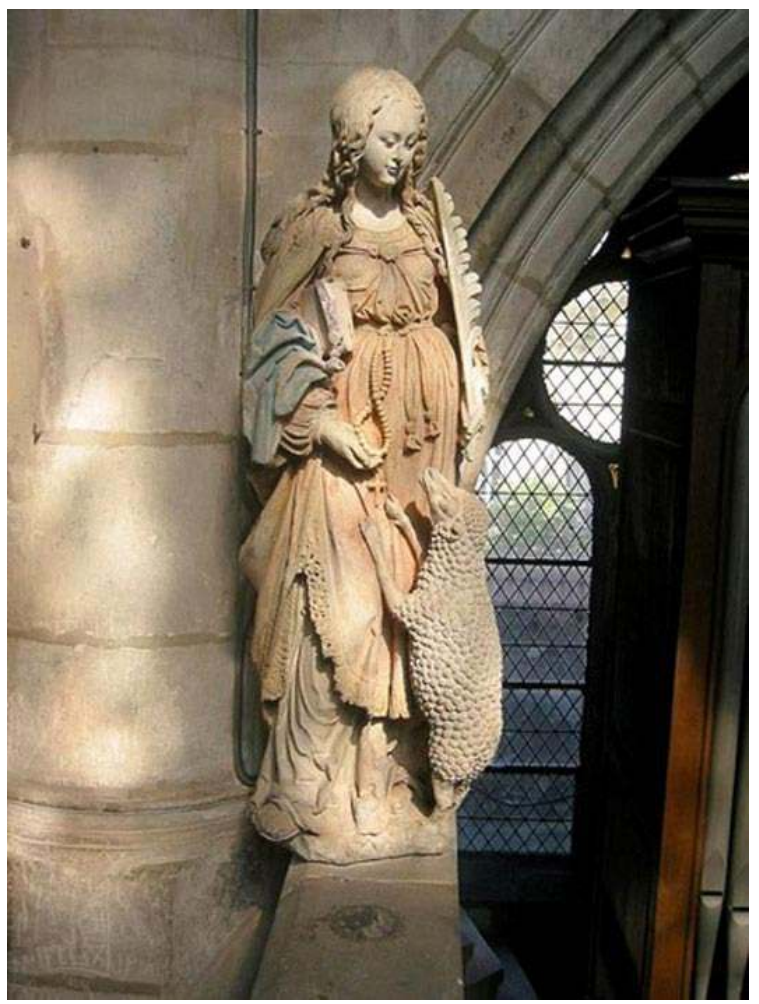

Statue de sainte Agnès et son agneau, Troyes, église Saint-Nicolas, XVle siècle.

Phot. M. Bennani @ Ministère de la Culture et de la Communication. Région Champagne-Ardenne. Département de l'Aube, 2003. 2983 statues ont été recensées; cinq œuvres représentent sainte Agnès. 


\section{Les attentes « gestionnaires »}

17 Pour une bonne gestion locale des objets recensés, les notices mentionnent le propriétaire, le niveau de protection, les éventuelles références bibliographiques, le degré d'exposition au vol et l'état de conservation ${ }^{10}$.

L'architecture du dossier électronique de l'Inventaire obligeant à créer une fiche "édifice» pour tout immeuble à l'intérieur duquel du mobilier est recensé, cette opportunité fut mise à profit par la conservation régionale des monuments historiques de Champagne-Ardenne et à la demande du service départemental de l'architecture et du patrimoine de l'Aube, pour dresser un bilan sanitaire sommaire de l'ensemble des églises du département ${ }^{11}$.

Une autre des finalités de l'opération étant de préparer les campagnes de protection à venir, la mention «à signaler » distingue les objets qui mériteraient d'être protégés ou, pour ceux qui le sont déjà, dont le niveau de protection mériterait d'être relevé ${ }^{12}$. (fig. $\mathbf{n}$ $\circ 5)$

Figure 5

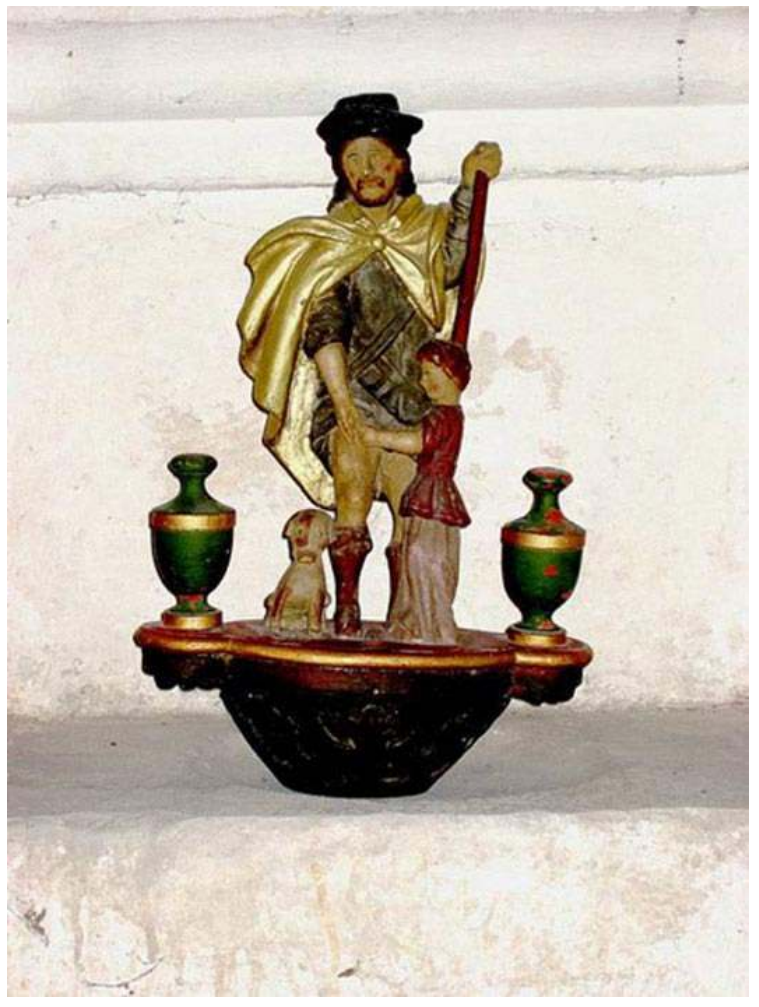

Bâton de confrérie : saint Roch à Voigny, XVIIle siècle.

Phot. J. Marasi et F. Griot ( ) Ministère de la Culture et de la Communication. Région ChampagneArdenne. Département de l'Aube, 2003. 362 bâtons de procession ont été recensés ; 116 œuvres, toutes dénominations confondues, représentent saint Roch.

L'enquête a été menée de janvier 2002 à avril 2005 par une équipe de huit chercheurs ${ }^{13}$

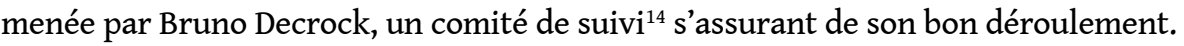

Les principaux points sur lesquels ce dernier eut à se prononcer furent : 
- l'établissement des rubriques de la fiche de recensement, en particulier les champs de gestion locale et leur utilisation

- les critères de sélection des objets, à partir d'un recensement très large opéré, en phase de test, sur cinq édifices

- les formes de restitution de la documentation constituée, les opérations de communication

- les propositions de compléments au marché primitif pour répondre à des évolutions rencontrées en cours d'enquête (en particulier le passage de 10000 à 12000 notices)

- la préparation des contacts avec les populations locales, avec les maires des communes ${ }^{15}$ - la validation de la méthodologie générale ; tant sur le terrain (types d'informations à ne pas oublier, prises de vues à privilégier...), qu'au moment de la saisie (méthode d'enregistrement des objets particuliers, types d'ensembles à retenir..). (fig. $\left.\mathbf{n}^{\circ} \mathbf{6}\right)$ (fig. $\mathbf{n}$ $\circ$ 7)

Figure 6

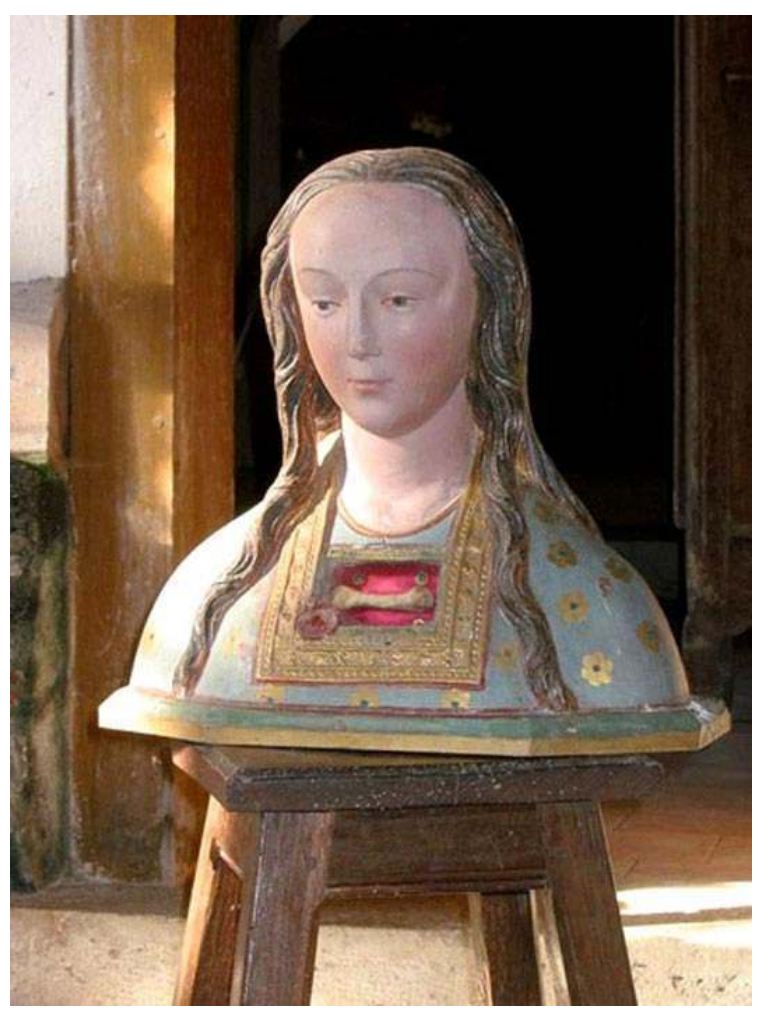

Buste-reliquaire de sainte Thuise à Dommartin, XVIIe siècle ( ?).

Phot. B. Decrock (C) Ministère de la Culture et de la Communication. Région Champagne-Ardenne. Département de l'Aube, 2003. Sainte locale, identifiée par inscription, et représentée deux fois seulement dans le recensement. Par ailleurs, 31 bustes reliquaires ont été recensés. 
Figure 7

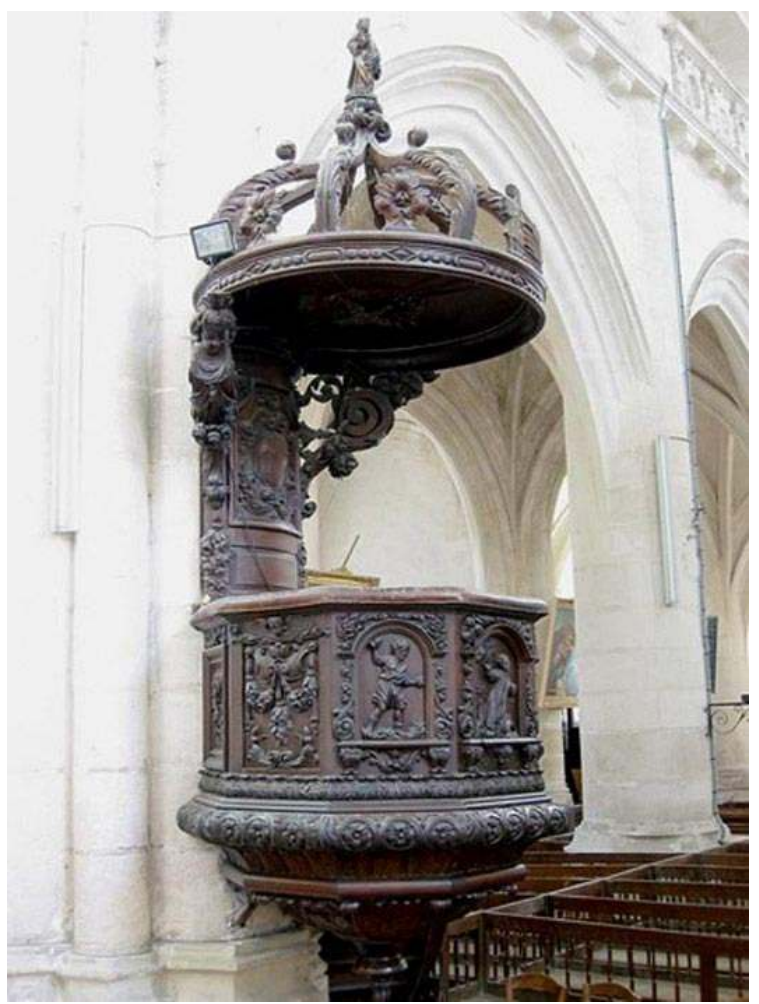

Chaire à prêcher de Bar-sur-Seine, 1689.

Phot. F. Griot @ Ministère de la Culture et de la Communication. Région Champagne-Ardenne. Département de l'Aube, 2003. 144 chaires ont été recensées.

\section{Les étapes de l'opération}

Grosso modo, l'opération s'est déroulée en trois phases :

- durant le premier semestre, ouverture des notices par la saisie ou la conversion des données déjà connues, mise au point avec le comité de suivi de la méthodologie et de l'organisation technique, enfin test sur cinq édifices tant de l'équipement (en particulier photographique) que des critères de sélection

- durant les deux années suivantes, alternance des campagnes de terrain durant la belle saison, et de temps de saisie et de mise en forme de la documentation pendant l'hiver

- durant les six derniers mois (plus trois mois complémentaires accordés après extension de mission pour le traitement des clichés anciens) furent menés : le dépouillement de la bibliographie, qui servit notamment à alimenter le chapitre «historique » des notices déjà existantes, les ultimes vérifications sur le terrain, les dernières identification de poinçons et d'armoiries. Des relevés d'églises avec localisation des œuvres recensées furent dressés avec le logiciel PhotoShop. (fig. $\mathbf{n}^{\circ}$ 8) (fig. $\mathbf{n}^{\circ}$ 9) 
Figure 8

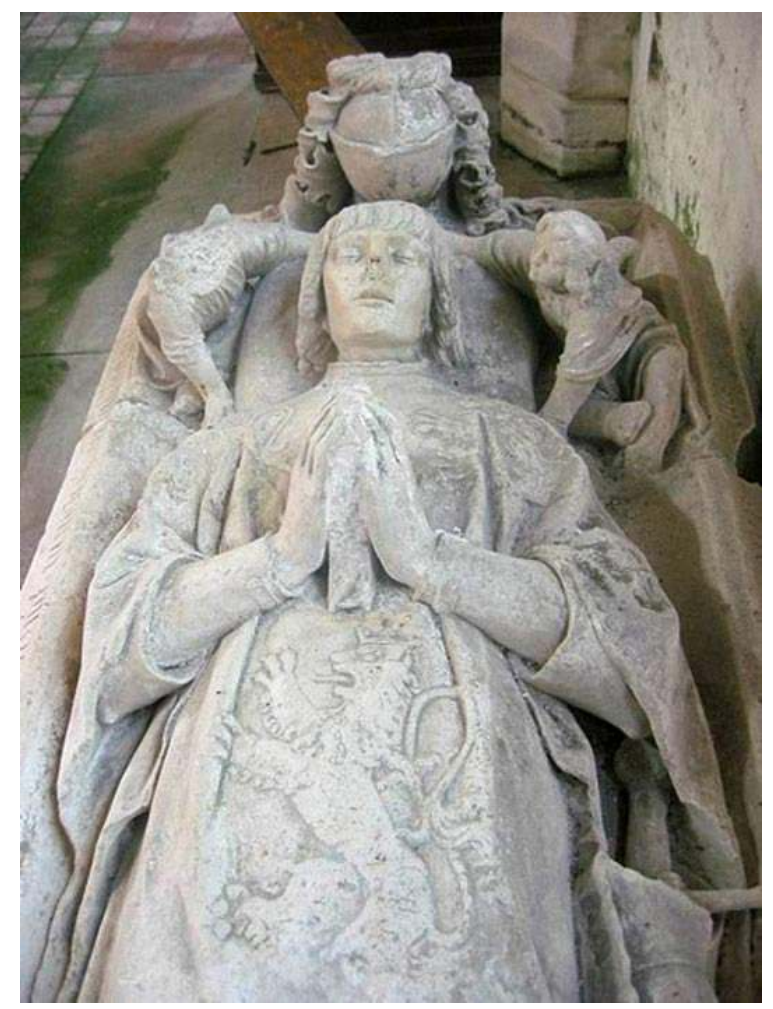

Tombeau de Pierre de Launoy à Dampierre, 1522 (détail).

Phot. B. Decrock (c) Ministère de la Culture et de la Communication. Région ChampagneArdenne. Département de l'Aube, 2002. Seuls cinq tombeaux avec gisant ont été recensés, mais les dalles funéraires sont beaucoup plus fréquentes : 473. 


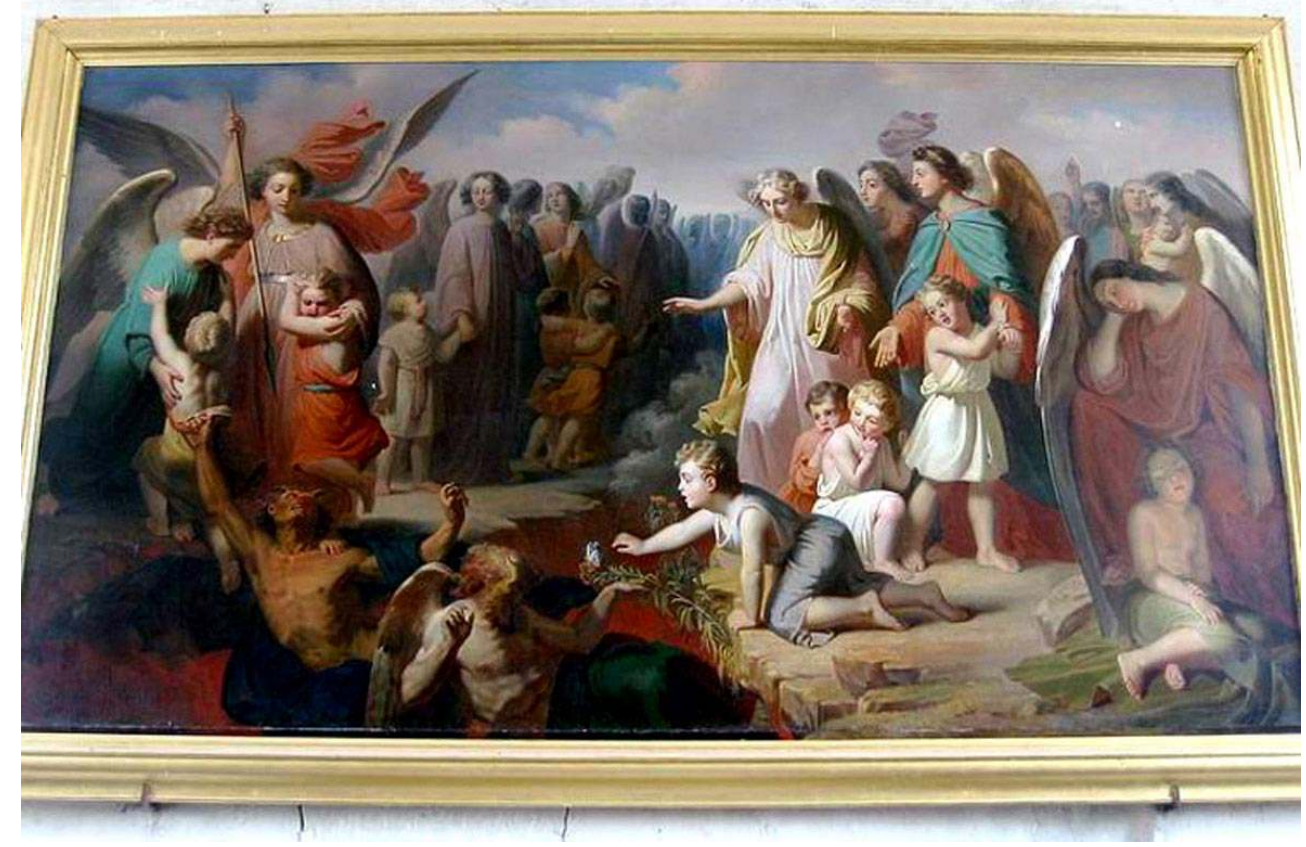

Tableau à Verrières, 1848, par Claude Thévenin : Les anges gardiens.

Phot. B. Decrock (c) Ministère de la Culture et de la Communication. Région Champagne-Ardenne. Département de l'Aube,2002. 1223 tableaux ont été recensés, non compris les tableaux d'autel.

\section{Quelques résultats et enseignements}

Disons-le d'emblée : il est trop tôt pour analyser en détail les données de cette enquête qui a permis de constituer un corpus d'œuvres et une masse documentaire sur lesquels pourront s'appuyer de nouvelles recherches, notamment universitaires.

Quelques chiffres montreront l'étendue du terrain parcouru et la richesse des églises visitées :

- 422 communes ont été prospectées ${ }^{16}$

- 551 édifices ont été visités; sur ce total on dénombre 449 églises ( $81,5 \%$ du total), 41 chapelles (7,5\%), 27 mairies ( $5 \%$; essentiellement en tant que lieux de dépôt d'œuvres provenant des églises) sans compter six presbytères, cinq maisons, trois musées, trois remises, trois établissements administratifs, trois hôtels, deux écoles, deux châteaux, un beffroi, la cathédrale et l'hôtel-Dieu de Troyes ...

- une moyenne de 22 objets fut recensée par édifice, 28 objets par commune prospectée. Mais on observe de très fortes disparités : la commune de Troyes rassemble à elle seule 1238 œuvres ${ }^{17}$, tandis qu'à l'autre extrémité de l'échelle, des communes comme Champsur-Barse, Cormost, Mesgrigny, Paisy-Cosdon n'ont donné lieu à l'ouverture que de deux ou trois fiches. A titre indicatif, toutes les communes possédant de véritables églisesmusées ont toujours fait l'objet de plus de cent notices : Bar-sur-Aube (207), Bar-sur-Seine (173), Chaource (171), Ervy-le-Châtel (136), Sainte-Savine (122), Mussy-sur-Seine (121), enfin Les Riceys (300 œuvres réparties entre trois églises et la mairie). 
Un total de 32545 photographies ayant été retenues, cela revient à dire que chaque objet est en moyenne illustré par deux ou trois images. (fig. $\left.\mathbf{n}^{\circ} \mathbf{1 0}\right)$

Figure 10

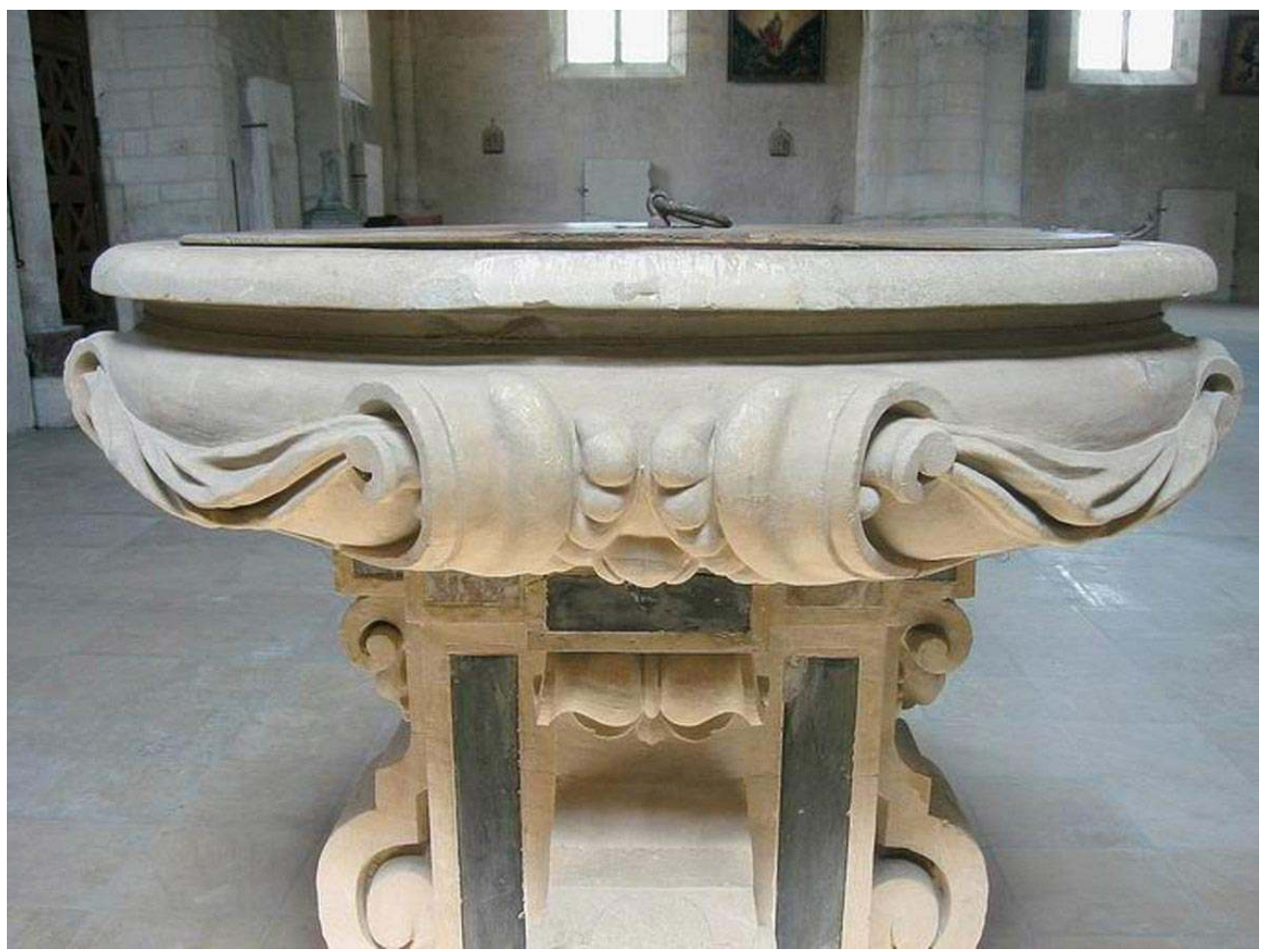

Fonts baptismaux de 1653 à Vendeuvre-sur-Barse (détail de la cuve).

Phot. F. Griot (c) Ministère de la Culture et de la Communication. Région Champagne-Ardenne. Département de l'Aube, 2003. 249 fonts baptismaux recensés.

\section{Comparaison entre les œuvres protégées et recensées}

Euvres classées ( 3500 unités ${ }^{18}$ après fractionnement des arrêtés de protection concernant des ensembles) :

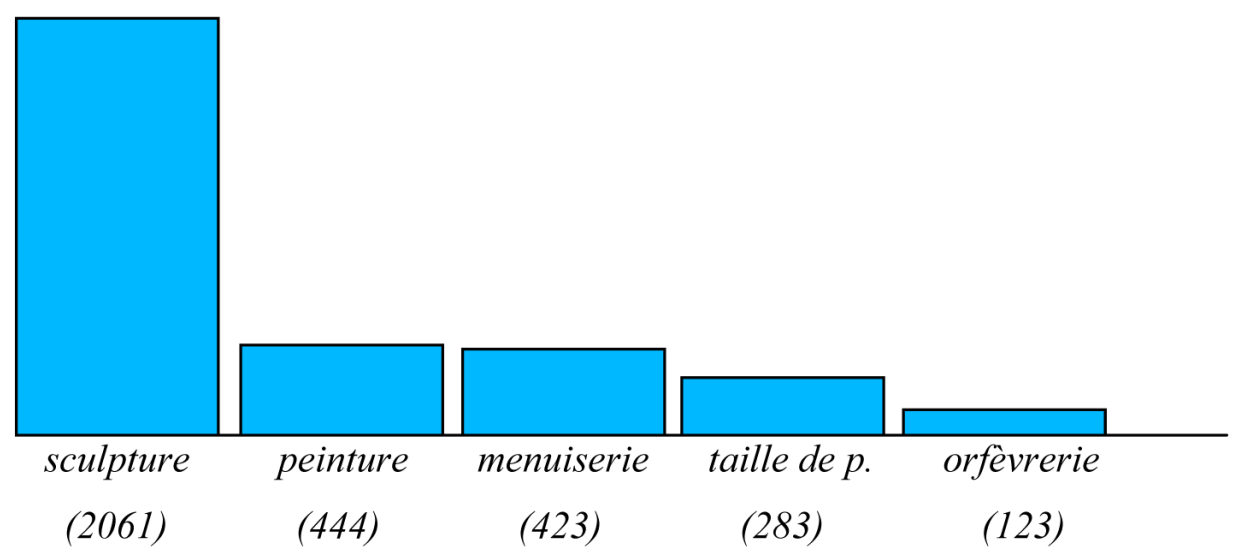


Fuvres inscrites (1441 unités) :

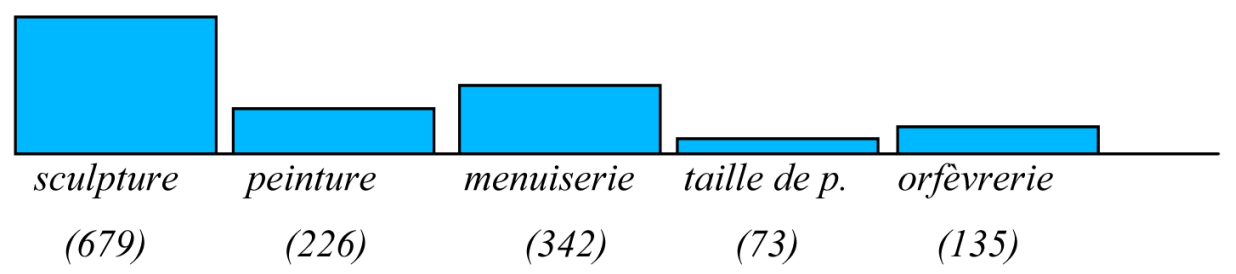

Cuvres repérées par Monseigneur Marsat (2563 unités) :

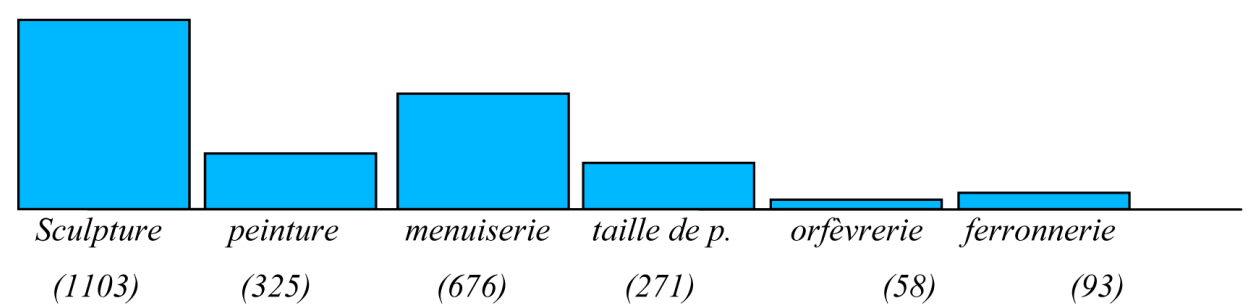

Fuvres supplémentaires recensées lors de l'enquête (4474 unités) :

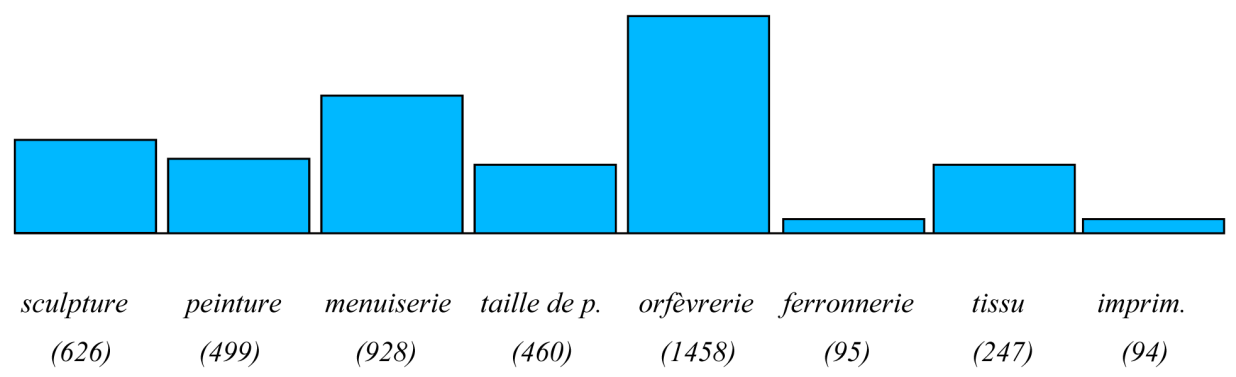

Les graphiques ci-dessus montrent des évolutions à la fois sensibles et néanmoins peu surprenantes entre œuvres classées, inscrites, anciennement connues ou recensées pour la première fois à l'occasion de cette enquête. La sculpture, catégorie reine dans les protections et recensements anciens, régresse en troisième position des œuvres nouvellement prises en compte, ce qui montre à la fois que le plus gros avait déjà été fait, mais aussi que des découvertes demeuraient possibles. La menuiserie, déjà bien représentée dans les repérages réalisés par le précédent CAOA, l'est également ici, tandis que les œuvres tissées (bannières, vêtements liturgiques) apparaissent pour la première fois en nombre significatif, tout comme les livres ; c'est cependant l'orfèvrerie qui occupe la première place de la nouvelle sélection, pour une raison facile à expliquer : en grande majorité du XIXe siècle, elle n'avait pas jusqu'à présent paru présenter un intérêt artistique suffisant. Cependant, bien qu'il s'agisse d'une production semi-industrielle, le métal précieux dans lequel ces pièces ont été réalisées les rend particulièrement vulnérables aux vols, ce qui suffit à justifier, s'il le fallait, leur prise en compte.

La répartition chronologique est elle aussi différente selon le degré de protection dont bénéficient les œuvres, ce qui ne saurait surprendre. Si le XVIe siècle représente $57 \%$ des œuvres classées et le XIXe siècle seulement 3,7\%, ces époques regroupent en revanche respectivement $24 \%$ et $23 \%$ des œuvres inscrites ( $31 \%$ datent du XVIIIe siècle), $27 \%$ et $17 \%$ des œuvres repérées par Monseigneur Marsat (33,5\% de ces dernières datent du 
XVIIIle siècle), et enfin 8,3\% et $55 \%$ des œuvres supplémentaires ajoutées par l'enquête, ce qui marque une inversion complète des répartitions chronologiques.

\section{Quelques « découvertes»}

Le nombre d'œuvres recensées étant très important, les "découvertes " furent nombreuses. Il ne s'agit pas d'en dresser ici une liste exhaustive. On peut cependant essayer de les classer par catégories car elles peuvent être de plusieurs types.

Tout d'abord les œuvres jusqu'alors inconnues : une statue d'ange en bois du XIIIe siècle à Verrières, deux statuettes de saintes du XVIe siècle, intégrées à une rocaille du XIXe siècle dans l'église de Pargues, des statues oubliées dans une cave, ou dans un placard de l'église, souvent en piètre état mais pouvant être de belle facture, par exemple à Bragelogne ou à Trouan-le-Grand. (fig. $\left.\mathbf{n}^{\circ} \mathbf{1 1}\right)$

Figure 11

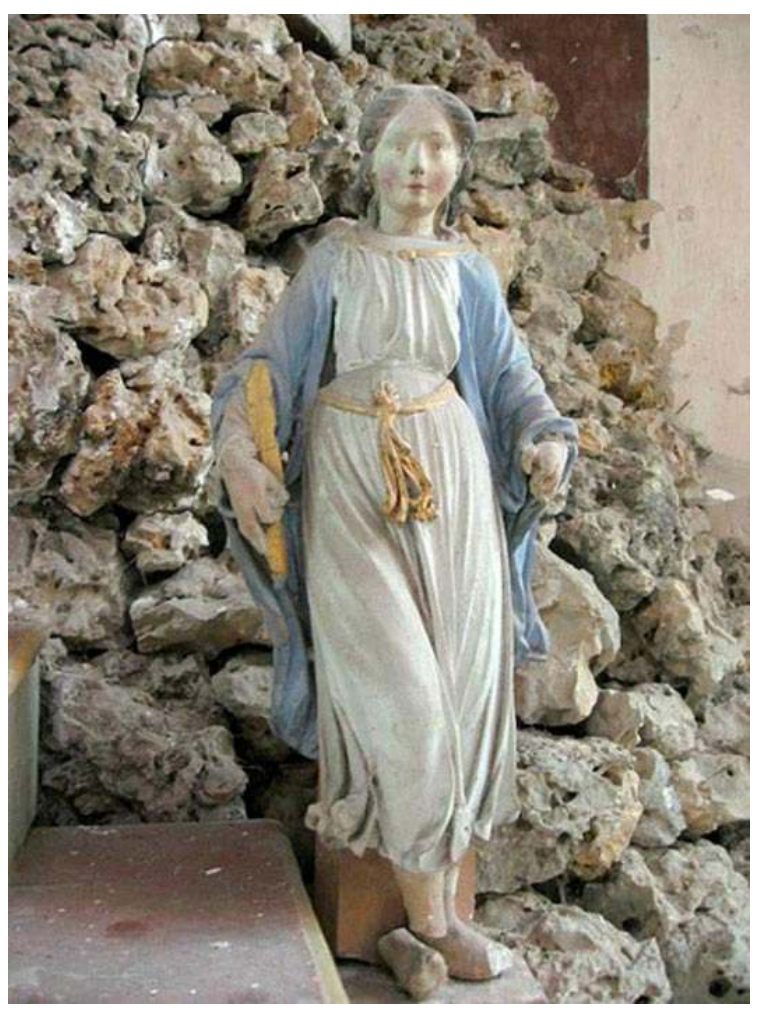

Petite statue de sainte non identifiée, XVle siècle ?, à Pargues.

Phot. B. Decrock (c) Ministère de la Culture et de la Communication. Région Champagne-Ardenne. Département de l'Aube, 2003.

Un autre type de découvertes concerne les attributions que l'on peut proposer, par exemple tel relief en pierre à Chaource que l'on peut manifestement situer dans la production de l'atelier dit de Vignory. Une étude stylistique plus poussée du corpus rassemblé permettra sans doute d'avancer dans la connaissance.

Par ailleurs, certains objets tout juste connus, mais non protégés, se sont parfois révélés être de véritables chefs-d'œuvre, tel un buste de sainte Madeleine trouvé à La LogePomblin, une statuette de saint Léger du XVIIe siècle à Montfey, ou un meuble de sacristie aux panneaux peints de la même époque à Courceroy. 
dernière catégorie tient en fait à l'évolution du regard porté sur les productions des siècles passés, réévaluation d'autant plus forte qu'il s'agit d'un passé récent. Ainsi, des œuvres, parfois dénigrées pour leur peu d'intérêt, sont apparues à l'observation être des pièces peut-être trop restaurées, mais aux qualités largement sous-estimées, comme, par exemple, les Mise au tombeau des églises de Ricey-Bas et d'Ervy-le-Châtel, mutilées et méconnues. Des objets parmi les plus récents, qui n'avaient pas été pris en compte par les enquêtes précédentes, sont d'une réelle valeur artistique, tel ce Christ de la Flagellation daté 1947, créé en mémoire des «victimes du bombardement de Chaource le 14 juin $1940 »$ et conservé dans l'église de ce village.

Certains domaines peu représentés, voire oubliés des repérages anciens ont enfin été introduits dans la liste des objets proposés à l'attention. C'est le cas par exemple, aux deux extrémités de la chronologie, des fonts baptismaux les plus anciens (souvent du XIIIe siècle), œuvres de tailleur de pierre, certes rustiques et sans grand décor, mais assez rares pour être recensées ; et, plus proches de nous, des pièces semi-industrielles, comme l'orfèvrerie du XIXe siècle, les livres imprimés anciens, les vêtements liturgiques.

\section{Les disparitions}

CAOA a l'obligation légale d'effectuer au moins tous les cinq ans un récolement des objets classés du département dont il a la charge. Dans la pratique, et faute de moyens, on sait que c'est rarement le cas. Une des motivations originelles de l'opération auboise était de réaliser ce récolement. Il permit de dresser un état précis des œuvres qui avaient disparu, soit depuis leur protection, soit depuis l'établissement du dernier fichier.

Les disparitions et vols avérés, bien qu'en nombre non négligeable, se sont révélés être un peu moins nombreux qu'on ne pouvait le craindre : 589 objets n'ont pas été retrouvés (512 œuvres déclarées disparues et 77 volées; plus 14 volées partiellement ${ }^{19}$ ), ce qui correspond à $7,8 \%$ des œuvres anciennement connues. (fig. $\mathbf{n}^{\circ} \mathbf{1 2}$ ) 
Figure 12

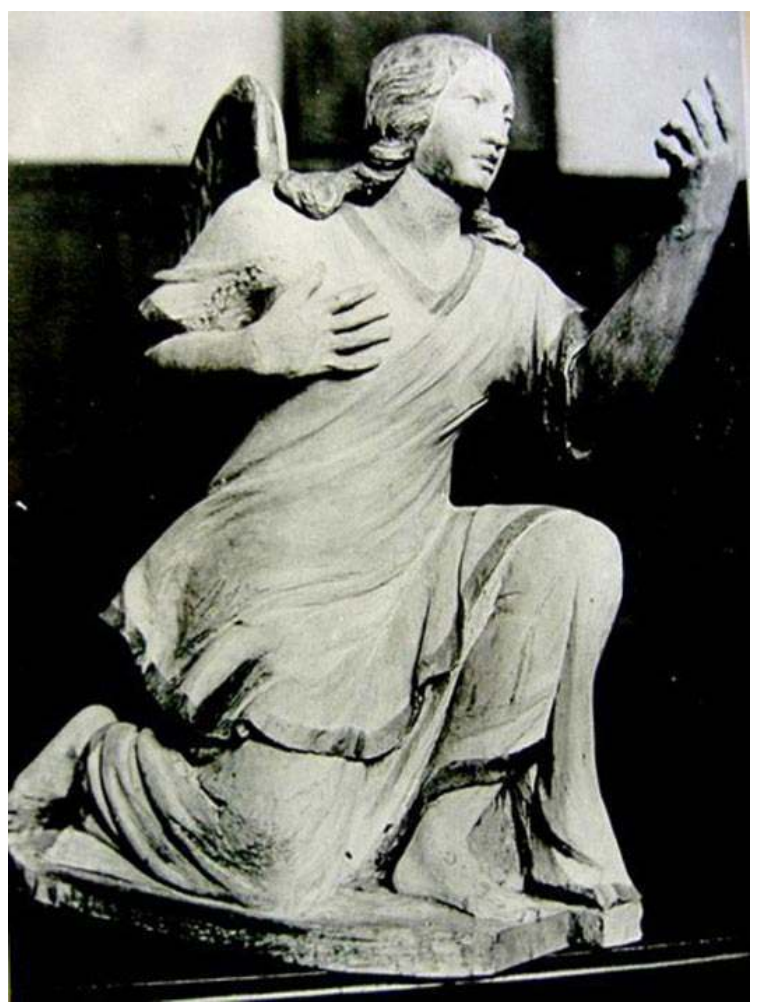

Une des deux statues d'anges du XVIIle siècle volés en 1967 à Saint-Benoist-sur-Vanne. Phot. SAP, médiathèque du patrimoine (c) CMN.

Il apparaît en outre que la protection - et notamment l'inscription - si elle ne représente pas une garantie absolue contre le vol, limite cependant très largement les disparitions qui semblent concerner prioritairement les œuvres peu connues et donc difficiles à retrouver.

\section{La programmation des futures séances de la commission départementale des objets mobiliers}

D'ores et déjà, la CDOM a commencé à examiner les œuvres non protégées mentionnées "à signaler ", et dont l'état était jugé mauvais ou très mauvais. Un premier lot a concerné la sculpture datée du XVIe siècle ou plus ancienne, soit une vingtaine d'œuvres, dont cinq seulement ont été retenues pour une inscription (dont deux avec un vœu de classement). Cette sévérité apparente s'explique par l'état de dégradation des œuvres non retenues, qui a paru trop avancé aux membres de la commission. Au total, toutes catégories et époques confondues, environ 200 notices d'œuvres non protégées, en mauvais ou très mauvais état, portent la mention "à signaler ». Ce chiffre est à multiplier par dix si l'on ne tient plus compte du degré d'urgence. Ce qui revient à dire que potentiellement le nombre des œuvres protégées pourrait être augmenté de $40 \%$, au maximum; mais de $10 \%$ seulement si le quota d'œuvres finalement retenues reste le même.

La mise en place programmée d'une délégation permanente de la CDOM devrait permettre d'établir des pré-sélections, pour faciliter et accélérer le passage de ces dossiers en commission. (fig. $\left.\mathbf{n}^{\circ} \mathbf{1 3}\right)$ 
Figure 13

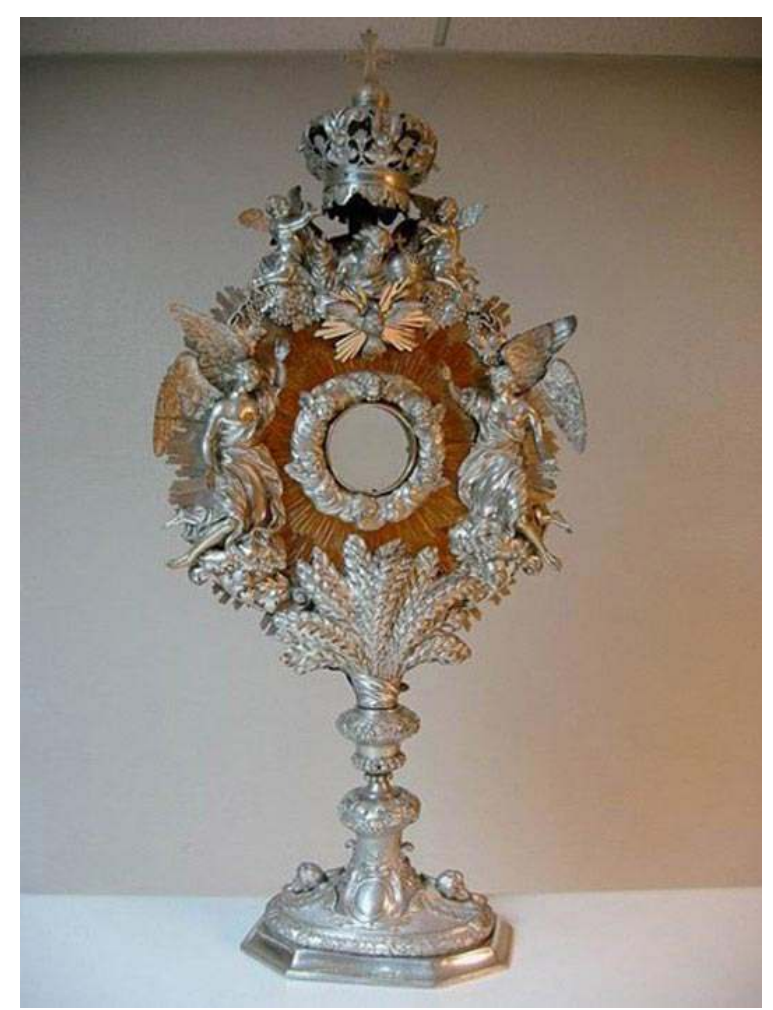

Ostensoir, Bar-sur-Aube, 1724.

Phot. F. Griot et J. Marasi @ Ministère de la Culture et de la Communication. Région ChampagneArdenne. Département de l'Aube, 2003.

\section{Les modes de restitution}

La documentation établie pourra donner lieu à quatre modes de consultation, soit successivement soit conjointement :

- sur le site internet du conseil général de l'Aube, grâce à la mise en ligne de la base en format HTML à partir du 19 septembre 2005, en accès limité réservé aux communes du département (connexion extranet) ${ }^{20}$

- sur les bases nationales du ministère de la Culture : consultation des notices Mérimée (architecture) et Palissy (objets), des images sur la base Mémoire. Cet accès, qui met à profit la sélection par lexiques mais perd une partie des liens hypertextes existants entre fiches et tables, orientera à terme vers le site du conseil général et ses accès spécifiques (lien vers l'adresse pérenne des données sélectionnées sur le site local)

- à partir de 2006 sur le site du conseil général, mise en ligne ouverte à tous (connexion internet) d'une version quelque peu bridée de la base ${ }^{21}$ mais utilisant tout son potentiel technique 22

- sur la base de gestion du $\mathrm{CAOA}^{23}$ comportant des champs spécifiques de gestion des œuvres (déplacements, restaurations ...), et donnant la possibilité d'effectuer des modifications sur la base source, telles des protections nouvelles, et permettant la mise à jour des bases en ligne. (fig. $\mathbf{n}^{\circ}$ 14) 


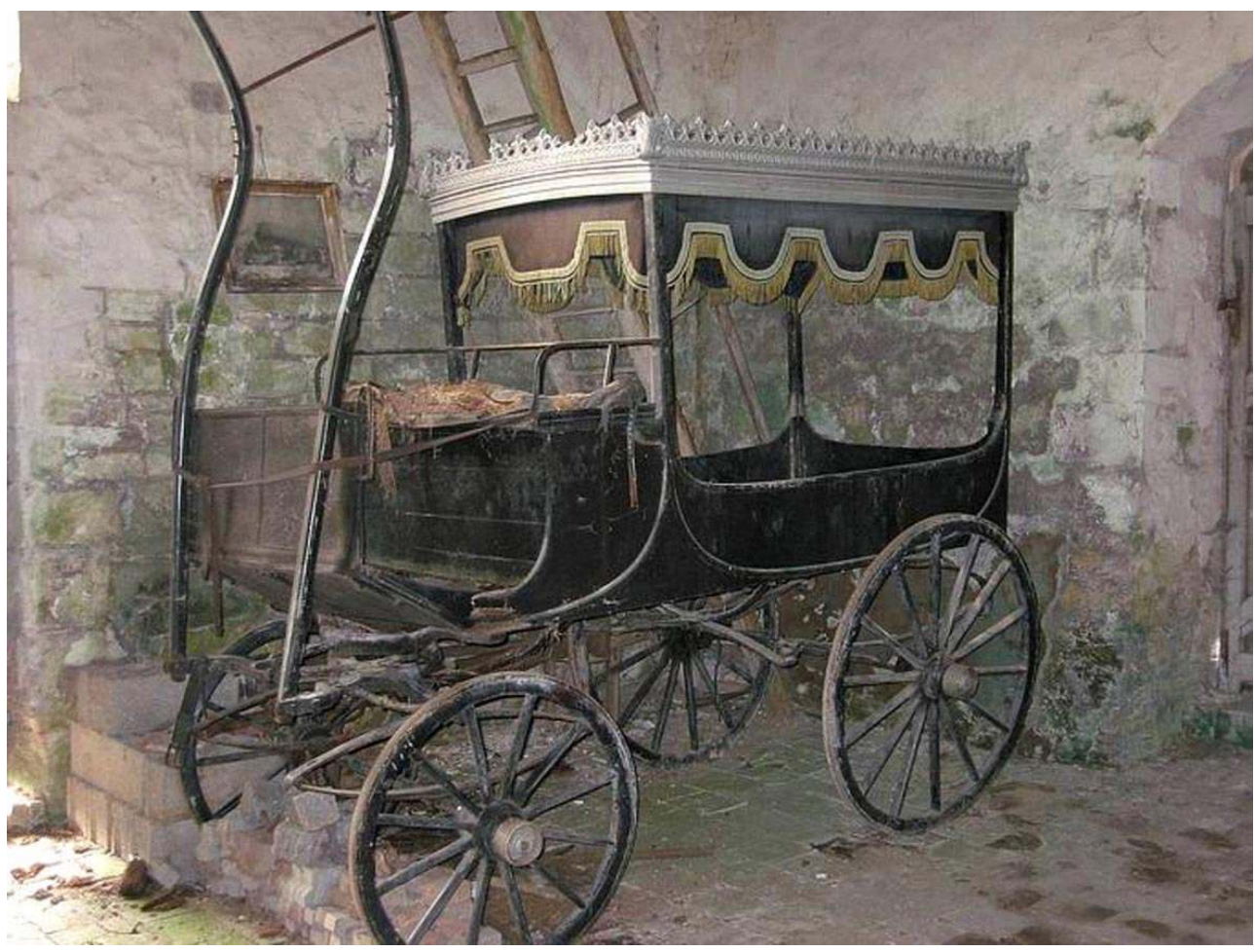

Corbillard à Fontaine-Luyères.

Phot. B. Decrock ( Ministère de la Culture et de la Communication. Région Champagne-Ardenne.

Département de l'Aube, 2003. 4 corbillards ont été recensés au cours de l'enquête.

\section{Conclusion}

40 Cette enquête ne trouvera sa pleine justification que si elle permet d'établir et de mettre en œuvre un vaste programme d'études, de protections nouvelles et surtout de restaurations. Il faudra veiller à ce que l'intérêt suscité sur place par les enquêteurs pour ce patrimoine ne retombe pas. De ce point de vue, le couronnement de l'opération devrait être une grande exposition consacrée à la sculpture troyenne : espérons que ce projet trouvera un écho favorable auprès des élus locaux. Sans doute la mise en ligne des résultats de l'opération y contribuera-t-elle.

41 La qualité du résultat obtenu a d'ores et déjà engagé l'Etat et la Région à proposer au département voisin de la Haute-Marne de se lancer dans la même aventure, opération qui vient de débuter cet été 2005 , avec les mêmes acteurs. 


\section{NOTES}

1. Le dossier électronique de l'Inventaire, conçu et développé par le service régional de Bretagne à partir de 1996 avant d'être progressivement mis à disposition des autres services, permet d'associer sous format numérique, tant en phase de constitution que d'archivage ou de consultation, les différentes informations collectées par l'enquêteur sur les œuvres : historique, description, photographies, bibliographie, etc.

2. Jusqu'au lancement de l'actuel contrat de plan Etat-Région, cette dernière ne subventionnait pas les actions de connaissance ou de restauration du mobilier protégé au titre des Monuments historiques, alors qu'elle le fait depuis les années 1980 pour les édifices.

3. Monseigneur Marsat, conservateur des antiquités et objets d'art de l'Aube de 1971 à 1989.

4. Service de la conservation régionale des monuments historiques. 12655 fiches objets ont été établies, auxquelles s'ajoutent 553 fiches architecture, le ratio s'établit donc à $35 €$ TTC par notice.

5. Quelques dizaines d'œuvres conservées dans les mairies, tel un coffre à Barberey-Saint-Sulpice, une paire de fauteuils ou un tableau à Bar-sur-Aube ; mais a priori un seul arrêté concernant un château : les boiseries d'une pièce du château de Dampierre. Mais aussi deux wagons à Romillysur-Seine, deux bornes (Neuville-sur-Seine et Bourguignon), des boîtes à pharmacie et autres pots ... (hôtel-Dieu de Troyes), quatre cadrans solaires, quatre pompes à incendie, quatre échelles en bois ...

6. A l'issue de l'opération, on n'arrivera qu'à un total de 184 œuvres du XXe siècle (soit $1,5 \%$ du total) : 59 en tissu (essentiellement des vêtements liturgiques et des bannières), 51 pièces d'orfèvrerie, 28 sculptures, 13 productions de menuiserie (bâtons de procession, confessionnaux ...), 10 peintures ...

7. Les fiches des verrières classées au titre mobilier, héritées de l'informatisation des arrêtés, n'ont pas été exclues du fichier général; ceci afin de permettre le basculement au moins à l'identique des fiches du domaine MH. Il n'en reste pas moins que ces vitraux - par ailleurs déjà compris dans l'inventaire du Corpus Vitrearum - n'ont pas fait l'objet d'un complément d'enquête sur le terrain. Une harmonisation des saisies des domaines MH et Inventaire serait souhaitable dans ce domaine. Reste que les verrières postérieures au XVII ${ }^{\mathrm{e}}$ siècle n'étaient pas recensées par le Corpus Vitrearum. A l'issue de l'opération, cette lacune parut regrettable, et il est prévu d'intégrer le vitrail récent dans l'opération comparable qui a débuté en Haute-Marne en août 2005.

8. La publication très prochaine, aux Presses universitaires de Rennes, de la thèse de Véronique Boucherat: Le rôle des modèles dans la production artistique en Champagne à la fin du Moyen Age, devrait permettre de donner un éclairage nouveau à l'ensemble de cette création.

9. Ponctuellement des dommages importants ont été à déplorer, notamment en 1944 : destruction de l'église d'Arcis-sur-Aube (et de son mobilier), de l'église d'Allibaudières, du couvert vitré de l'église de Villenauxe-la-Grande ...

10. Seuls deux champs à mots-clefs furent introduits pour permettre la gestion : l'un précisant l'exposition de l'objet au vol (scellé, lourd, en hauteur, encombrant, sacristie fermée ...), l'autre indiquant son état apparent de conservation sur une échelle allant de 0 (très bon état apparent) à 5 (très mauvais état apparent).

11. La constitution de fiches et de photos sur ces 552 édifices contenants (dont 449 églises) n'étant pas prévue au marché primitif, celui-ci fit l'objet d'une commande supplémentaire passée par la CRMH d'un montant de $7400 €$ TTC. 
12. Pour les œuvres déjà classées, la mention « à signaler » souligne leur intérêt majeur au regard de l'histoire de l'art.

13. Recrutés sur la base d'une formation universitaire minimale de quatre années d'histoire de l'art, ils participèrent à ce travail pour un total de 30000 heures : Raphaële Caumont de Mesquita, Sandrine Pagenot, François Griot, Julien Marasi, puis Maya Bennani, Isabelle Havard, Gwenaëlle Cabille, Audrey Mondolot, Elise Ernest, Delphine Mercier, Marion Masson. Une dizaine de stagiaires bénévoles vint leur prêter main forte : Sabine Laillet, Rudy Garret, Audrey Mondolot (IUP de Troyes) ; Céline Le Merlus, Eve Lepaon, Simon Delobel (Ecole du Louvre) ; Clara Jouany, Airy Cazin, Nolwen Parousy (Université de Nancy II); Marie-Laurence Clarac, (Paris IV); Gwenaëlle Cabille (Paris I). En outre, plusieurs agents de l'inventaire général furent mis à contribution à différents stade de l'opération et nous tenons ici à les remercier : Pierrick Brihaye, du SRI Bretagne, pour les adaptations de l'outil Renabl, dont il est l'inventeur, aux besoins de l'enquête auboise; Laurence de Finance, responsable du mobilier au département Recherche, Méthode et Expertise à la direction de l'architecture et du patrimoine, pour avoir répondu aux questions d'ordre méthodologique et lexical ; Laurence Dellière, responsable de la base Palissy, pour avoir aidé à la solution des problèmes posés par le transfert des données de Renabl dans la base du ministère ; et aussi Sophie Annoepel, Jean Davoigneau, Aline Magnien, Judith Kagan ... Une mention spéciale doit être réservée à Benoît Guillot, étudiant en imagerie numérique de l'IUT de Reims qui mit au point un logiciel de retouche automatique de nos images d'objets particulièrement performant.

14. Afin de suivre et de valider le travail du chargé d'études, un comité de suivi fut mis en place, réunissant le conservateur des antiquités et objets d'art du département, directeur des archives départementales, le conservateur régional des Monuments historiques, le conservateur des monuments historiques en charge du mobilier à la DRAC, le conservateur régional de l'Inventaire, ainsi que la chargée de mission de la Région pour le volet «patrimoine bâti » du contrat de plan. La préparation et les comptes rendus des réunions étaient établis par le chargé d'études. Neuf réunions se sont tenues, de janvier 2002 à janvier 2005, sur un rythme bimestriel durant la phase de démarrage, puis deux fois par an en moyenne par la suite. Elles se tenaient soit aux archives de l'Aube soit à la DRAC.

15. En plus du courrier envoyé en mars 2002 à tous les maires du département par le président du conseil général pour les informer du démarrage de l'opération, une réunion d'information fut réalisée à l'intention des médias à l'église de Verrières le 3 juillet suivant. La presse locale (L'Est É clair) se fit à partir de là l'écho régulier de la progression de l'enquête, de même que, bien entendu, la revue du Conseil général, l'Aube Nouvelle, qui consacra notamment un numéro spécial aux résultats de l'opération ( $n^{\circ} 52$, été 2005). A la demande de certaines communes (Bar-surSeine, Chaource ...) des séances de présentation à la fois de l'opération en cours et des particularités du patrimoine local furent organisées; certaines manifestations scientifiques et culturelles locales - colloque du centre Pithou à Troyes en mai 2005... - furent l'occasion de présenter à nouveau l'action entreprise et les premiers résultats obtenus.

16. Soit un peu moins que les 453 communes et hameaux que compte le département, certains ne comportant pas d'églises (communes de création récente, notamment dans le canton de Bouilly). 17. Cathédrale (332) ; églises Saint-Nicolas (124), Sainte-Madeleine (123), Saint-Rémy (99), SaintPantaléon (98), Saint-Jean (91), Saint-Urbain (86), Saint-Martin-ès-Vignes (74), Saint-Nizier (73) ; hôtel-Dieu (64), etc.

18. Les chiffres qui suivent sont issus d'un premier état de la base mais ne sont susceptibles que de modifications mineures.

19. Souvent des statuettes de retable.

20. Les informations disponibles seront complétées à terme par un dossier technique, sorte de "vade mecum» de la conduite à tenir face à une œuvre en danger (état dégradé, vol) et comportant les références de l'ensemble des acteurs patrimoniaux (institutionnels, restaurateurs 
...). La CRMH de Champagne-Ardenne a produit une première maquette de ce document, dont la réalisation fut confiée à Audrey Mondolot.

21. Les données « confidentielles » telles que la mise en sécurité - ou non - seront masquées.

22. Soit une version de consultation par SDX de la version XML; soit par le biais d'un système de consultation développé localement ; l'année 2006 devant être mise à profit pour sa mise au point. Il s'agira à cette occasion de décider du type d'exploitation du géoréférencement : soit à partir du système de calques (ArcView) produit grâce à GeoRenabl ; soit - ou inclusivement - en faisant interpréter directement par le SIG du conseil général les coordonnées Lambert remplies avec ce même outil.

23. Un accès partagé avec la CRMH (DRAC) est envisagé.

\section{RÉSUMÉS}

De 2002 à 2004 une équipe de chercheurs a mené à bien le recensement de l'ensemble du patrimoine mobilier des églises du département de l'Aube, l'un des plus riches de France par le nombre d'œuvres classées ou inscrites. Cette opération sans précédent par sa rapidité et les moyens mobilisés a concerné 551 édifices et permis l'établissement de plus de 12000 fiches au moyen du "dossier électronique " développé par l'Inventaire général. Cette enquête a été possible grâce à la mobilisation conjointe du Département de l'Aube, chef de file de l'opération, de la Région Champagne-Ardenne et de la Direction Régionale des Affaires Culturelles, dont la conservation des Monuments historiques et le service de l'Inventaire ont accompagné sur le plan méthodologique le travail du chargé d'étude.

From 2002 to 2004, a team of researchers undertook a recording survey of all the furniture and furnishings in the churches of the Aube department, one of the richest in France in terms of its protected religious heritage. The operation was unprecedented in terms of rapidity and the means mobilised. It covered 551 buildings and led to the completion of 12,000 individual notices, using the electronic recording files developed by the services of the Inventaire général. The project was led by the heritage services of the department, with help from those of the region (DRAC Champagne-Ardenne), in particular the historic monuments service and the Inventaire général, this last giving guidance on the methodological aspects of the programme.

\section{INDEX}

Mots-clés : objet, sculpture, mobilier, inventaire, recensement, récolement, dossier électronique, Aube, Champagne-Ardenne, monuments historiques, églises, objets liturgiques, art sacré

Keywords : furniture, furnishing, church, heritage, inventory 


\section{AUTEURS}

\section{XAVIER DE MASSARY}

Conservateur du patrimoine. Inventaire. Région Champagne-Ardenne. xavier.demassary@culture.gouv.fr

\section{BRUNO DECROCK}

Chercheur.decrock.tau@free 